\title{
BIOLOGIA MOLECULAR NA EDUCAÇÃO BÁSICA: EXPLORANDO POSSIBILIDADES DE APRENDIZAGEM EM UM ESPAÇO NÃO FORMAL
}

\author{
Daniel F.B. Ovigli; Nelma R.S. Bossolan; Leila M. Beltramini
}

\begin{abstract}
Resumo:
Um dos objetivos assumidos pela Coordenadoria de Educação e Difusão Científica do CBME é contribuir tanto para a disseminação quanto para o aprendizado de técnicas e conceitos básicos na área de Biologia Celular e Molecular, de modo que o público possa ter o interesse científico despertado, bem como associar estes avanços com sua realidade. Nesse contexto, foi implantado um Espaço Interativo, aberto ao público escolar e não escolar, com diversas atividades que abordam conceitos básicos dessas áreas, passando por algumas doenças consideradas negligenciadas pelos laboratórios farmacêuticos e que são objeto de pesquisas do CBME, até as tecnologias atuais envolvidas no estudo das biomoléculas. Assim, o presente trabalho objetiva a apresentação desse espaço considerando as possibilidades de aprendizagem em Biologia Celular e Molecular por ele oferecidas, bem como sua contribuição no processo de divulgação científica enquanto um centro de ciências. Resultados de avaliações preliminares também são discutidos considerando questões relativas ao interesse despertado pelas atividades, à importância da temática e ao tipo de linguagem utilizada na exposição.
\end{abstract}

Palavras-chave: biologia molecular, educação não formal, museus de ciências, biotecnologia

\section{MOLECULAR BIOLOGY IN BASIC EDUCATION: EXPLORIANG LEARNING POSSIBILITIES IN AN NON FORMAL SPACE}

\begin{abstract}
:
One of the goals of the Coordination of Education and Dissemination of CBME is to contribute not only for the dissemination but also the learning in Cell and Molecular Biology, so that the public can have their scientific interest aroused, and associate these advances with their reality. In this context, an Interactive Space was implanted, opened to the scholar and non scholar public, with different activities that approach from basic concepts of these areas, some diseases considered neglected by pharmaceutical laboratories and that are subject of researches of CBME, to current technologies involved in the study of biomolecules. Thus, the present study aims to present this space considering the possibilities of learning in Cell Biology and Molecular Biology that are offered, as well as their contribution to scientific dissemination as a science center. Results of preliminary evaluations are also discussed considering questions related to the interest aroused by the activities, the importance of the themes and the kind of language used in the exhibition.
\end{abstract}

Keywords: molecular biology, non formal education, science museums, biotechnology 


\section{INTRODUÇÃo}

\subsection{Educação em espaços não formais: um panorama...}

O ensino de ciências configura-se como uma prática social que vem sendo cada vez mais desenvolvida em espaços não formais de educação, tais como museus e centros de cultura científica [1]. Vários autores do campo educacional discutem a importância e necessidade da elaboração de políticas e estratégias que efetivamente auxiliem a compreensão do conhecimento científico por meio de experiências extra-escolares [24].

Espaços não formais ganham cada vez mais destaque diante do aumento constante e acelerado da quantidade de informações que se apresentam à sociedade do conhecimento [5]. A escola, no entanto, tem encontrado dificuldades para disseminar todas as informações e reflexões necessárias à compreensão desse atual paradigma, em particular no que diz respeito à educação em Ciências. Considerando-se o fato de que a instituição escolar acumula uma grande quantidade de funções sociais, este é um dos motivos que cria barreiras para uma maior flexibilidade curricular [6].

Dessa forma, a educação em espaços não formais compreende aspectos que os tornam fundamentais para a promoção de uma proposta educativa pautada na diminuição da distância entre os avanços da Ciência e Tecnologia e o currículo escolar, características perfeitamente cabíveis aos avanços trazidos pela moderna Biologia Molecular, bem como suas implicações para a Biotecnologia.

O caráter de não formalidade das instituições museais também permite uma maior liberdade na seleção e organização de conteúdos e metodologias, o que amplia as possibilidades de interdisciplinaridade e contextualização, bem como atualização frente ao currículo praticado na Educação Básica [7-8]. Por esse motivo, eles possuem um grande potencial para promover a motivação para o estudo e aprendizado das Ciências [1].

Desta forma a educação não formal praticada em museus de Ciências deve aliar informação, ensino-aprendizagem e entretenimento em prol da ampliação da cultura e construção de valores, a partir do exercício da cidadania. Para isso ela deve também "trabalhar para desmistificar a Ciência e motivar o pensamento crítico e investigador na compreensão-ação dos problemas sociais" [6], caracterizando a relevância da integração Ciência, Tecnologia e Sociedade (CTS) no ensino [9].

No entanto ainda são tímidas, em especial no Brasil, as iniciativas de investigação que tenham por objeto a educação não formal e a divulgação científica [1]. Assim, no escopo de atuação da Coordenadoria de Educação e Difusão Científica do Centro de Biotecnologia Molecular Estrutural (CBME), um CEPID (Centro de Inovação Pesquisa e Difusão) da FAPESP, montou-se um Espaço Interativo, situado no próprio prédio-sede da Difusão, localizado em um imóvel anexo ao Centro de Divulgação Científica e Cultural (CDCC/USP), na cidade de São Carlos/SP.

\subsection{O Espaço Interativo do CBME}

Este espaço abriga atividades interativas e painéis ilustrativos sobre os temas correlatos ao Centro. Estas atividades são integradas e complementares às atividades em desenvolvimento pela referida Coordenadoria. O tema "Microrganismos", utilizado como eixo temático da exposição, faz parte dos conteúdos programáticos dos ensinos fundamental e médio e também aparece em diferentes momentos quando da abordagem do tema Biologia Molecular e Biotecnologia.

O "Espaço" conta com um painel histórico sobre os principais fatos e eventos relacionados à Microbiologia, com destaque aos pesquisadores brasileiros da área, 
além de um segundo painel, que apresenta cinco doenças causadas por microrganismos e que são objeto de estudo do CBME, enquanto um CEPID. Algumas técnicas utilizadas no estudo de biomoléculas tais como PCR (reação em cadeia da polimerase), bem como métodos moleculares de diagnóstico de doenças são apresentadas neste painel. Atividades interativas também foram implementadas: diversidade dos microrganismos em uma gota de água, doença de Chagas, observação de células animais (por meio da raspagem da mucosa bucal) e vegetais (planta conhecida popularmente como trapoeraba roxa ou Elodea, uma planta comumente utilizada em aquários) e utilização do software "Células Virtuais" e montagem da molécula de DNA utilizando o kit "DNA e RNA: construindo as moléculas da vida" ${ }^{1}$. Três expositores também integram o "Espaço": neles são abordados conteúdos relativos às doenças transmitidas por vírus, fungos e bactérias, bem como aplicações de microrganismos em biotecnologia.

Assim, o presente trabalho objetiva apresentar as possibilidades de aprendizagem a partir do ambiente expositivo proposto, bem como resultados de avaliações preliminares realizadas junto ao Espaço Interativo do CBME.

\section{MATERIAL E MÉtOdOS}

Nessa etapa tomou-se por base um levantamento realizado por Palmieri et al (2005), que investigou os principais interesses e dúvidas de alunos da Educação Básica das redes pública e privada da cidade de São Carlos (SP), nas disciplinas de Ciências e Biologia, quanto à temática "Microrganismos". Professores do referido nível de ensino também responderam questionários acerca da metodologia utilizada quando da abordagem dos temas em questão, bem como as possibilidades de transposição didática utilizadas. As temáticas apontadas como sendo de maior interesse por parte dos alunos incluíam microrganismos causadores de doenças, modelos tridimensionais de microrganismos e suas aplicações biotecnológicas.

A proposta que permeou a estruturação do Espaço Interativo inclui a organização do conhecimento a partir de situações de aprendizagem que tenham significado para 0 aluno, permitindo que ele construa um instrumental para agir em diferentes contextos e, principalmente, em situações de seu cotidiano, englobando não apenas conceitos, mas também procedimentos e valores [11]. Trata-se, portanto, de inverter o que tem sido a tradição de ensinar Ciências como "conhecimento descontextualizado, independentemente de vivências, de referências a práticas reais, e colocar essa ciência como "meio" para ampliar a compreensão sobre a realidade, favorecendo a interpretação de fenômenos biológicos como instrumento para orientar decisões e intervenções no meio em que vive" [11].

\section{RESULTADOS}

As atividades foram planejadas e dispostas no Espaço Interativo de modo a possibilitar ao visitante uma compreensão gradual e contextualizada dos assuntos.

Em um primeiro momento a visita é dirigida à realização da atividade "Observação de células animais e vegetais", objetivando a familiarização com o conceito de célula, que permeia grande parte da exposição. Modelos tridimensionais de célula vegetal, bem como um painel relativo à célula animal também compõem o cenário expositivo. O visitante é, então, convidado a sistematizar tal noção por meio da comparação com conteúdo do software "Células Virtuais", que aprofunda o conceito de célula mostrando as principais organelas presentes e possibilita a resolução de exercícios. Núcleo e

1 Ferramentas instrucionais desenvolvidas pela Coordenadoria de Educação e Difusão Científica do CBME. 
material genético também são abordados havendo, inclusive, um kit "DNA e RNA: construindo as moléculas da vida" sobre a bancada, visando à aproximação do visitante com tal estrutura bem como sua função. Modelos tridimensionais da membrana plasmática, mostrando sua constituição lipoprotéica também são mostrados. Destaca-se a intervenção do mediador na elucidação de questões levantadas pelos visitantes, notadamente acerca da função dessas moléculas biológicas na composição da membrana. Oficinas desenvolvidas pelo CBME também são incluídas em visitas de alunos e professores da Educação Básica. A prática "Extração do DNA de Morango" tem início com o entendimento acerca da estrutura celular para, sob orientação do mediador, realizar procedimentos que tenham por finalidade o isolamento do DNA do morango.

A abordagem das mais recentes técnicas envolvidas no estudo das biomoléculas fazse presente quando da apresentação da temática "Biotecnologia e o cotidiano". O objetivo, mais uma vez, reside em conferir significados para o assunto, por meio de temas diretamente vinculados ao cotidiano dos visitantes. Para tal apresenta-se, inicialmente, processos de fabricação de gêneros alimentícios como pão, iogurte, vinho e queijo. O bicho da seda na produção de tecidos e uso de feromônios no combate à dengue são utilizados para compor o cenário referente à biotecnologia. 0 intuito reside em mostrar que a mesma biotecnologia que inclui a engenharia genética e de proteínas e as diversas formas de manipular moléculas e seres microscópicos com finalidades específicas também estão presentes em produtos alimentícios comuns no dia-a-dia. Assim, as discussões propostas pelos mediadores do Espaço Interativo também objetivam reconstruir historicamente a biotecnologia, visto tirarmos proveito dos microrganismos desde as primeiras civilizações para que não incorram na associação da biotecnologia como sendo uma "revolução atual" da Ciência mostrando que, na atualidade, a novidade está na forma como os microrganismos são manipulados. Particularmente nos últimos 50 anos o ser humano vem aprendendo cada vez mais sobre o mecanismo de funcionamento das moléculas que compõem os seres vivos. Novas técnicas e conhecimentos se fazem presentes, emergindo estudos que englobam a Biologia Molecular Estrutural. A biotecnologia "atual" presente no Espaço Interativo aborda a resolução de estruturas de proteínas, por meio de painéis e esquemas 3-D e possibilita a visualização de cristais de lisozima (uma enzima presente na lágrima) em uma lupa. Modelos de enterotoxina da bactéria Escherichia coli e de uma HIV protease também são mostrados, visando à exemplificação das técnicas de resolução de estrutura de proteínas bem como sua importância no planejamento racional de drogas farmacêuticas. A Tecnologia do DNA recombinante é mostrada em painéis que tratam dessa técnica na produção de insulina e hormônio do crescimento.

As últimas ações que nortearam a consolidação do Espaço Interativo do CBME trataram de avaliá-lo junto ao público escolar por meio de questionários respondidos por professores e alunos da Educação Básica. Quatro professores e 28 alunos foram convidados a responder às questões, em visitas previamente agendadas e acompanhadas por mediadores do Espaço Interativo.

Fundamentalmente, o questionário aplicado aos docentes incluiu o levantamento de dados acerca de sua formação inicial e continuada (perfil do professor), bem como sua atuação profissional (tempo no magistério, componente curricular que ministra e carga horária semanal, além de aspectos que fizeram com o docente se interessasse em utilizar este tipo de atividade extraclasse). Neste mesmo questionário, os docentes também foram indagados sobre os painéis e atividades presentes no Espaço Interativo, vinculando-os à organização, ao potencial do "Espaço" para estimular a curiosidade e incentivar a criatividade e ao tipo de linguagem utilizada na exposição. As atividades interativas também foram analisadas quanto à adequação com relação a 
sua realização nas condições propostas (tempo, número de alunos envolvidos, presença de monitores). As respostas fornecidas pelos docentes foram particularmente úteis tendo em vista o levantamento de dados acerca da freqüência com que o professor utiliza atividades extraclasse, bem como a preparação prévia dos alunos para a visita.

As atividades que mais despertam a curiosidade dos alunos visitantes incluem "Microrganismos em uma gota de água" (78,5\%), observação de células animais e vegetais $(75 \%)$ e Construção da molécula de DNA (78,5\%). Expositores e painéis explicativos referentes à Biotecnologia e o cotidiano foram indicados como "ótimos" ou "muito bons" por $100 \%$ dos respondentes e os itens "estímulo à curiosidade" e "atuação do mediador" representam, respectivamente, 71,4\% e $82,1 \%$ das respostas dos alunos. $100 \%$ dos professores visitantes trabalhavam os assuntos abordados no Espaço Interativo em sala de aula e ressaltaram o vínculo das atividades com o cotidiano, bem como a adequação da linguagem à transposição didática dos temas em questão.

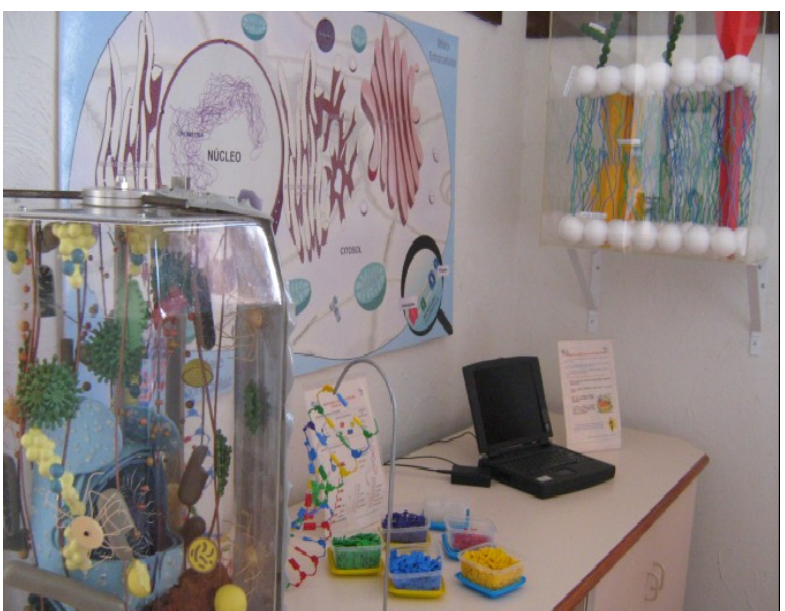

Fig. 1 - Manipulação do software "Células Virtuais" e construção da molécula de DNA

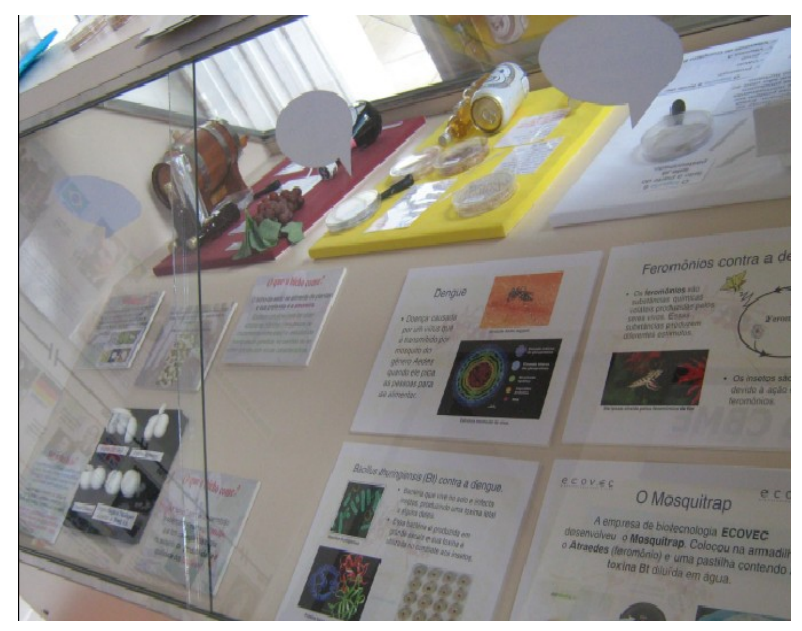

Fig. 2 - Expositor "Biotecnologia e o cotidiano"

\section{DISCUSSÃO DOS RESULTADOS}

Alguns alunos enfatizaram a exposição de mais modelos tridimensionais de microrganismos, bem como informações complementares acerca de determinadas doenças que já estão contempladas no Espaço Interativo: nesse contexto destaca-se a relevância do vírus HIV (causador da AIDS), citado em alguns questionários. Além disso, a exemplificação de outras técnicas utilizadas em Biologia Molecular e o oferecimento de mais oficinas foram categorias apontadas nas respostas.

As atividades interativas "Microrganismos em uma gota de água", "Visualização de células animais e vegetais", "Construção da molécula de DNA" e a observação de percevejos transmissores da doença de Chagas destacam-se nas respostas de alunos e professores.

A utilização de modelos para explicar processos biológicos que ocorrem em nível molecular tais como o transporte de nutrientes através das membranas celulares, a organização do código genético, a duplicação do DNA, a transcrição do RNA e a síntese de proteínas, bem como as tecnologias de manipulação do DNA e a participação da engenharia genética na produção de alimentos e fármacos integram temáticas a serem (re) pensadas no processo de estruturação do Espaço Interativo. 


\section{CONSIDERAÇÕES FINAIS}

Dessa forma, o trabalho de avaliação de um espaço não formal deve ser contínuo e, levando-se em consideração o Espaço Interativo do CBME, a avaliação tende a consolidar-se como formativa, visto que objetiva-se o levantamento de informações sobre a eficácia dessa experiência ainda durante seu desenvolvimento, orientando alterações e norteando caminhos no processo de divulgação científica da temática em questão.

A educação não formal, por ter uma organização mais flexível, possui um importante papel para a ampliação da cultura científica dos cidadãos. Mas, para conseguir popularizar seu trabalho, a presente pesquisa tem indicado a importância do estabelecimento de uma forte parceria com as escolas de Educação Básica, já que estas são instituições com maior capacidade de promover a continuidade do trabalho educativo desenvolvido no museu. A relação museu/escola aponta para a complementaridade, entendida não como forma de uma instituição suprir deficiências da outra e sim como uma relação que amplia, pela interação, as possibilidades educativas.

Para que a visita atinja seus objetivos educativos é necessário que museu e escola sejam efetivamente parceiros, contribuindo no processo de alfabetização científica do público visitante, seja ele escolar ou não escolar. Nesse sentido, algumas questões merecem maior estudo e devem orientar ações educativas por parte da Coordenadoria de Educação e Difusão Científica do CBME em um futuro próximo. Tais ações incluem desenvolvimento de material de apoio e orientação ao professor, de modo que a visita ao Espaço Interativo não se configure como um evento pontual e sem continuidade em sala de aula, lócus principal da intervenção. O papel de atividades nesses espaços também deve estar claro para o professor.

Temos consciência de que a consolidação do trabalho aqui apresentado depende de muitos outros aspectos que vão além da estrutura formal da exposição e da metodologia utilizada em sua estruturação. Nossa capacidade de colocar em prática um bom atendimento ao visitante bem como a possibilidade de manutenção e constante renovação das atividades e painéis presentes no "Espaço" e a elaboração de instrumentos de avaliação capazes de indicar as dificuldades e orientar novos caminhos são alguns dos desafios que nos aguardam para as próximas etapas.

\section{REFERÊNCIAS BIBLIOGRÁFICAS}

[1] MARANDINO, M.; SILVEIRA, R.V.M.; CHELINI, M.J.E.; FERNANDES, A.B.; GARCIA, V.A.R.; MARTINS, L.C.; LOURENÇO, M.F.; FERNANDES, J.A.; FLORENTINO, H.A. (2003) A Educação Não Formal e a Divulgação Científica: o que pensa quem faz? In: IV Encontro Nacional de Pesquisa em Ensino de Ciências ENPEC, 2003, Bauru. Atas do IV Encontro Nacional de Pesquisa em Ensino de Ciências - ENPEC.

[2] FALK, J. H. (2002) The contribution of free-choice learning to public understanding of science. INCI, v.27, no.2, p.62-65.

[3] FENSHAM, P. (1999) School science and public understanding of science. International Journal of Science Education, v.21, n.7, p. 755-763.

[4] JENKINS, E.W. (1999) School science, citizenship and the public understanding of science. International Journal of Science Education, v.21, n.7, p. $703-$ 710.

[5] HARgReAVES, A. (2004) O Ensino na Sociedade do Conhecimento: a educação na era da insegurança. Artmed Editora. Porto Alegre. 
[6] GUIMARAES, M.; VASCONCELLOS, M.M.N. (2006) Relações entre educação ambiental e educação em ciências na complementaridade dos espaços formais e não formais de educação. Educar em Revista, Jan/Jun, n.27, p.147-162.

[7] VIEIRA, V, BIANCONI, M. L.; DIAS, M. (2005) Espaços não-formais de ensino e o currículo de ciências. Ciência e Cultura, v.57, n.4, p.21- 23.

[8] GASPAR, A. (1993) Museus e centros de Ciências - Conceituação e proposta de um referencial teórico. Tese (Doutorado em Educação) - Faculdade de Educação, Universidade de São Paulo. São Paulo.

[9] BRASIL. (1998) Secretaria de Educação Fundamental. Parâmetros Curriculares Nacionais: terceiro e quarto ciclos do ensino fundamental; ciências. Brasília: MEC/ SEF, v. 4.

[10] MARANDINO, M. (2002) A Biologia nos Museus de Ciência: a questão dos textos em bioexposições. Ciência e Educação, v.8, n.2, p. 187-202.

[11] BRASIL. (2002) Secretaria de Educação Média e Tecnológica. Parâmetros Curriculares Nacionais para o Ensino Médio: Ciências da Natureza, Matemática e suas tecnologias. Brasília: MEC/SEMTEC. 